\title{
Redesigning Physical Education in Scotland
}

\author{
David Kirk, Farid Bardid, Cara Lamb, John Miller, Eishin Teraoka \\ University of Strathclyde, Glasgow, UK
}

\section{Introduction}

Physical education (PE) has a firmly established place in Scottish schools as evidenced by several key indicators: (1) Inclusion in the "core curriculum" since the early 1970s; (2) A national examination ('certificated') of PE, lending it the same status as other senior high school subjects for university entrance; (3) Specialist PE teachers, originating with founding of the Dunfermline College of Physical Education (for women) in 1906 and then the Scottish School of Physical Education (for men) in 1932; (4) Professional support for specialist teachers (e.g. newly graduating teachers gain access to Masters level qualifications with government funding and PE teachers enjoy parity of pay and promotion prospects with teachers of other school subjects); and (5) PE teacher education programs attract many more qualified applicants than can be offered places, resulting in an oversupply of PE teachers.

Given this description of the situation in Scotland, and with Lawson's Introduction as an evaluative framework, it might be tempting to conclude that the status quo is justifiable and incremental improvements, not radical redesign, comprise the agenda in Scotland. Indeed, advocates of appreciative inquiry (e.g. Enright et al, 2014) can find much to rejoice about, including McMillan (2017) who challenged 'unfair' accounts of teachers' practices.

Appearances, however, can be deceptive. Although there is much to celebrate about PE in Scottish schools, teachers would be hard-pressed to provide evidence, beyond their personal observations, of pupils' learning during the broad general education (BGE) phase for ages three15. 
Moreover, PE teachers' professional socialization and working conditions are not ideal. Novice teachers are as likely as teachers from other countries to experience the 'wash-out effect' of any radical reform impulses they might harbor due to the reality shock of the first two years of employment (Thorburn and Gray, 2010). Recruits' subjective warrant (Dewar \& Lawson, 1984) for PE teaching remains as powerful in today's Scotland as it did in the United States during the early 1980s. A love of sport, a desire to work with people, and being outdoors are key components.

Meanwhile, external challenges loom. Children aged three to six years, particularly those living in multiple deprivation, are at risk of motor development delay (Goodway and Rudisill, 1997). They are unlikely to be supported optimally in practicing and developing their motor skills because specialist expertise in movement and PE is lacking, especially in early childhood education and primary education. What is more, PE teachers may not be well equipped to provide the education needed by children with mental health problems (Teraoka et al., 2017).

The multi-activity curriculum and its subject matter organizing principle remain influential within the wider configuration of physical education-as-sport techniques (Kirk, 2010; Thorburn and Gray, 2010). This institutionalized form limits what might be achieved within the BGE (preschool to middle school) and senior (high school) phases of pupils' school careers. It shapes PE thought and practice at all levels of school and higher education, making it difficult for new initiatives to take root.

On the other hand, the relative professional freedom of PE teachers in Scotland enables local responses to global problems such as physical inactivity, precarity, and poor mental health among young people. As such, and echoing Lawson, we propose key principles for PE redesign in Scottish schools. All optimize the educational benefits to pupils, whilst supporting teachers in 
their professional work and development. We view this agenda as systems change undertaken in Scotland's policy context.

\section{The Education System in Scotland}

From the beginning, Scotland has had its own systems for Education, Finance and the Law. The Education system has retained this independence, and Acts of Parliament specific to Scotland are required to introduce new legislation. Thirty-two local authorities are charged with operating schools and employing teachers, while remaining in compliance with national policy.

At the age of five, children begin primary school, which they attend for seven years. At the age of 12 , they move to secondary school for a further four years, with an optional two years of senior high school. Early Years provision, known as early childhood education and preschool in other nations, is also available for children under five years of age, It also is operated by the local authorities.

At the ages $15 / 16$ and $17 / 18$, young people take the first and second set of national exams, the latter of which permit matriculation to higher education. It should be noted that individuals can leave school at the age of 16 (Smith, 2013).

$\mathrm{PE}$ is configured in accordance with this context. It is a required subject at all levels of the school system up to age 16, with provision for approximately two hours per week. In primary school, generally classroom teachers teach PE. However, some larger primary schools employ a specialist physical PE, and 'Active Schools' coordinators also offer support for additional physical activity and sport provision. In secondary schools, only specialist teachers teach PE. 


\section{Curriculum for Excellence}

Scotland's national school curriculum Curriculum for Excellence (CfE) was implemented in 2010 to provide learners with opportunities to develop knowledge, skills and attributes for life, learning and work (Scottish Government, 2009). This purpose is encapsulated in CfE's 'four capacities': successful learners, responsible citizens, effective contributors and confident individuals. Two phases provide structure: (1) broad general education (BGE), which is the compulsory phase of schooling; and (2) the senior phase, where pupils can gain national qualifications for positive leaver destinations beyond secondary school.

In the BGE phase, learning is organized into eight curricular areas. PE is located in the area of Health and Wellbeing (HWB), which covers mental, emotional, social and physical aspects. Significantly, HWB is a core learning area within the curriculum along with literacy and numeracy, and it is the responsibility of all teachers (Scottish Executive, 2006).

Each curricular area has a set of experiences and outcomes underpinning curriculum planning. PE experiences and outcomes are set alongside those for physical activity and sport. Benchmarks further clarify these experiences and outcomes and support teachers in assessment of pupil learning (Education Scotland, 2017). Table 1 provides a summary.

Insert Table 1 Here

The statements in Table 1 fall under the category 'Personal Qualities' in the curriculum documentation. All may contribute to four domains of learning (physical, social, cognitive and affective), although such a comprehensive contribution depends on teachers' enactment of these learning outcomes. Significantly, these organizing statements provide teachers with professional freedom to challenge the status-quo at a time when appropriate. 
However, and despite reports of good pedagogical practices by Her Majesty's Inspectorate of Education, a traditional skill-focused and teacher-directed approach continues to dominate PE in Scotland (Thorburn and Gray, 2010). The influence of this traditional approach on learners' perceptions of competence is evident in the persisting dichotomy of 'sporty' and 'non-sporty' identities (Mitchell et al., 2015).

In light of the holistic framework and purpose of the CfE, this standardized type of teaching approach is not the best choice. In Building the Curriculum 1, the following is written about learning and teaching in HWB: "Acquiring skills, knowledge and understanding about health and wellbeing, however, is not enough. The aim is that young people should develop a commitment to promoting their own health and wellbeing throughout their lives" (Scottish Executive, 2006, p. 10).

If obtaining skills, knowledge and understanding is insufficient, would a skill-focused programme be the best interpretation of the present curriculum? Redesign may therefore be plausible, if not desirable, but with manifest challenges. For example, although it may seem possible to challenge the status quo by simply providing teachers more professional freedom, teachers are also known to engage in 'acts of curriculum maintenance' (Lawson, 1988). Thorburn and Gray (2010) suggest that, in order to promote real change, it may be important to work with teachers in the reform of their fundamental beliefs about teaching, learning and curriculum.

\section{National Qualifications in Physical Education}

Pupils are offered PE in Scottish secondary schools as a high-stakes assessment-based subject leading to the award of national certificates. These senior phase certificates open up postschool learning and career opportunities, including university entrance. Certificated PE is on a 
par with other school subjects. The examination-based curriculum was first introduced to Scottish secondary education in 1999, bringing together subject qualifications into one multilevel framework for pupils (Bryce, 2003). In 2014, a further wave of reform established national qualifications for pupils ages 15-18 years (National 4, 5 and Higher certificates) in an attempt to improve transition from the BGE phase into certification, and to increase attainment levels across curricular areas (Thorburn, 2017).

The 2014 initiatives posed significant challenges for teachers and included major changes to course content, structure and assessment. Currently, National 5, taken around age 16, is formally assessed through a pupil-focused portfolio. Pupils are assessed in two practical activities within schools, with grading accuracy and consistency quality-assured through external verification. This process involves highly credible teaching staff visiting schools, observations of a selection of practical performances, and crosschecking against SQA certified standards that the school is accurate in its assessment.

The current Higher certificate, taken at age 17 or 18, involves practical assessment in one physical activity and one summative written examination of 90 minutes. The examination challenges pupils to describe, explain, evaluate and analyze different forms of data collection methods, intervention approaches to improve personal performance and evaluation tools.

For National 5 and Higher courses, students currently receive five timetabled classes of 50 minutes per week. Two involve classroom-based 'theoretical' lessons.

When Thorburn (1999) asked pupils if they 'were doing real PE today' as they did classroom-based work, s/he discovered that pupils' engagement was invariably poorer compared to practice-based sessions. Later, Thorburn and Collins (2006) found that pupils preferred physical activity lessons with follow-up homework tasks to classroom-based lessons with no 
homework tasks. This research indicates a discrepancy between pupils' preferences and mandated requirements.

Even so, many teachers would support the argument that specific contact time for classroom-based topics is required to further pupils' understanding of PE content, particularly at Higher level (Thorburn, 2017). The SQA (2014) states that the Higher course of PE supports pupils' development of a range of complex skills in challenging contexts as well as their ability to analyze $\mathrm{r}$ personal performance and apply this knowledge to improve it.

More recently, formal assessment for national certificates has become a priority. Teachers hold certificated PE in high regard, but several tensions have limited its overall impact, in particular the expectation that teachers deliver a curriculum constructed by agents and agencies external to the school environment. While many teachers do not necessarily wish to be involved in the curriculum development process, they express a desire to receive appropriate training and resources from central agencies (MacPhail, 2007).

PE teachers are particularly performance-proud and want to be seen to be strong practitioners in the senior phase of schooling. However, the BGE phase complicates their work. This phase remains the fundamental focus for all teaching staff. Through effective learning and teaching senior phase uptake and quality of pupil performance should naturally follow.

Leaders anticipated challenges. Early in the development of certificated PE, Brewer (2003) warned that physical educators should be wary of becoming 'trapped by certification' to the detriment of the BGE phase. Thorburn's (2017) recent "insider reflections" suggest this may already have happened. 


\section{Responding to external challenges: motor development in the early years}

Jess and Collins (2003) noted that the PE of young children in Scotland had become a topic of public interest as the $21^{\text {st }}$ Century dawned. Unlike many other countries, they claimed that specialist PE teachers were in primary schools in many parts of Scotland, supported by 'Active Schools' coordinators within a Sport Scotland/Youth Sport Trust initiative.

This special situation contrasts with the more common one in other nations. In these nations the generalist classroom teacher has responsibility for PE and is often unprepared for this task.

It was in this context that Jess and colleagues at the University of Edinburgh developed the Basic Moves programme, a fundamental movement skills intervention for pre-school and lower primary age children focused on locomotor and object control skills. This ambitious programme of pupil learning, underpinned by a 'dynamic, non-linear and emergent' pedagogy (Thorburn and Gray, 2010, p. 42), and teacher professional development, remains a special innovation.

Jess and Collins (2003, p. 115) emphasized importance of data collection, starting with early years education and continuing thereafter. "It is crucial that evidence from projects of this nature is available to influence the on-going debate that will help the PE profession identify the best way forward in the future." Unfortunately, Jess and colleagues apparently have not heeded their own recommendation for data collection and published research. In the ensuing years, they have emphasized teacher professional learning (e.g., Jess et al., 2014). While this focus is important, evidence of the effects of the programme on young people is required in order to inform and maintain public and political interest and debate. 
Despite public recognition of the importance of young children's movement experiences and a favourable and supportive professional environment, this initiative appears to have made limited progress. This situation is unfortunate, since the issue has not gone away.

Writing in 2010, Thorburn and Gray (2010, p. 34) noted: "There has been some acknowledgment within Scottish education that many pupils have poor movement skills." What tends not to be acknowledged within this cadre of writing in Scotland is that some pupils, especially ones living in areas with multiple deprivation, have comparatively greater needs for fundamental motor skills programmes in the early years.

In fact, motor development delay (MDD) is one important risk factor for children living in poverty (Goodway and Rudisill, 1997), and it is associated with sub-optimal outcomes. Young children who experience delay in their motor development are more likely to be adversely affected in terms of motor learning and cognitive functioning by the end of primary school and beyond (Lopes et al, 2013; Piek et al., 2008). Left unaddressed, delayed motor development in early childhood results in a reduced capacity to engage fully in physical activity and an increased risk of long-term poor health outcomes. MDD becomes a barrier to leading a physically active and healthy life (Stodden et al, 2008).

PE's aims and outcomes can be framed accordingly. It has been well-established that fundamental motor skills do not develop naturally in children, for example through free play, and need to be fostered in an appropriately structured environment (Gallahue et al., 2012).

Despite Jess and Collins' (2003) positive appraisal of the resources available to primary schools in Scotland for early years movement programmes, it would appear that targeted initiatives in schools serving children living in multiple deprivation are required as part of PE's improvement and redesign. A recent report on the Active Schools programme in one region of 
Scotland reveals that 'funding and resources' and 'fragility of staff and volunteering team' remains key challenges to the effectiveness of such programmes (Active Schools South Ayrshire, 2017).

\section{Responding to external challenges: mental health and wellbeing in adolescents}

In the past decade, researchers in PE have focused their attention on the affective domain of health, especially in adolescents. The affective domain refers to individuals' psychological and emotional wellbeing. The CfE provides several benchmarks of learning outcomes in the affective domain. One of these is Personal Qualities, encompassing motivation, confidence and self-esteem, determination and resilience, responsibility and leadership, respect and tolerance, and communication (Education Scotland, 2017). These affective attributes are recognized increasingly as important learning outcomes of PE (Thorburn, 2018)

Despite this recognition, important work remains. Reports suggest that mental wellbeing has declined among Scottish young people over time (Black and Martin, 2015). According to the Health Behaviour in School-aged Children (HBSC) survey in 2014, the percentage of children with at least two psychological complaints (e.g., difficulty sleeping; feeling nervous) in the previous week had increased since 2006 (Cosma et al., 2016). Additionally, Cosma et al. (2017) investigated the relationship between mental wellbeing and bullying victimization among Scottish adolescents using the HBSC survey data between 1994 and 2014. They found that bullied children were less likely to feel happy and confident, with bullying victimization rates increasing during that 20-year period.

While learning outcomes in affective domain have previously been viewed as byproducts of PE, pedagogical models such as Sport Education and Teaching Personal and Social Responsibility have focused specifically on affective benefits (Kirk, in press). Recent research 
offers important details about program drivers. For example, Mitchell, Gray and Inchley (2015) conducted a longitudinal qualitative study focusing on the change of Scottish girls from disengagement to engagement in PE. They found that providing a choice of activity promoted students' feelings of autonomy since the students can choose activities in which they felt competent, a finding amplified by Oliver and Kirk (2015).

Because mental health issues among young people have been a growing concern in Scotland, these findings regarding PE's affective benefits are timely.

So too is Quennerstedt's (2008) proposal that physical educators adopt a salutogenic approach. From this perspective, PE can promote health through developing motor skills, social interactions, empowerment and enjoyment. It is not only how long or how often adolescents are physically active that is important to their health. It is also a matter of what they do with the activity to understand the meaning within movement (Standal, 2015). In this view, a redesign challenge and opportunity in Scotland is the development of "pedagogies of affect" predicated on the idea that affective learning is not merely a PE program by-product. It is as a central educational outcome.

\section{Conclusion}

There is much to celebrate about the situation of PE in Scotland. It is a core aspect of the national $\mathrm{CfE}$, with a legislated requirement for a minimum of two hours per week for each young person during the BGE phase. Additionally, in the senior school, PE is offered within the diet of high-stakes examination subjects where it enjoys parity of esteem with other more traditional school subjects. There is a clear case to be made for PE's contribution to the development of motor competence among younger children living in multiple deprivation, and to the mental health and wellbeing of adolescents. 
Even with this positive situation, a case can be made for the redesign of PE. We conclude with two points to illustrate how even in apparently favorable situations, redesign may be necessary, possible and desirable.

The first builds on a distinctive strength — namely, the professional freedom available to teachers to interpret and implement the $\mathrm{CfE}$ as appropriate and beneficial for their pupils. However, this freedom depends on teachers' skills and capacities to respond to global issues such as physical inactivity, childhood obesity and health and wellbeing for all in ways that fit their local contexts.

The risk is that freedom and autonomy translate to teacher isolation. A wealth of curriculum innovation literature indicates that teachers working in isolation rarely realize the full range of benefits. Thus, one of the key redesign principles for PE in Scotland must be support through what Day and Townsend (2009) call 'networked learning communities'. Membership of such communities may vary according to locale and circumstances, but would involve some mix of key stakeholders such as teachers, pupils, parent organizations, policy makers, teacher professional associations, and university researchers.

A second redesign principle accompanies the recommendation for networked learning communities. It is founded on importance of the routine data collection and use as well are regular recording and reporting of evidence regarding the educational benefits of PE programmes. In Scotland, important co-requisites are in place. For example, the national certificate programme in senior high school produces highly formalized records of pupil learning, and so there is a ready-made opportunity for evidence gathering.

The challenge for teachers and researchers is to exploit this opportunity, using it as a facilitator for collaboration. At the other end of the school, the Basic Moves initiative in the early 
years and primary schools provides an example of what appears to be a missed opportunity to generate evidence of pupils' learning. This invaluable evidence that might inform teacher judgement and school planning as well as public opinion and public policy. .

Taxpayers generously support school PE in Scotland, with teachers' annual recurrent salary bill in excess of $£ 80$ million pounds per year. With this level of public investment, redesign should be a central component of a process of ongoing and sustainable curriculum renewal, with the explicit purpose of supporting all young people to learn to value the physically active life. 


\section{References}

Active Schools South Ayrshire, 2017. Evaluation Report. http://www.activeschoolssa.co.uk/wpcontent/uploads/2017/07/AS_Survey_v1.pdf. [Accessed 8 January 2018].

Atencio, M., Jess, M., and Dewar, K., 2012. 'It is a case of changing your thought processes, the way you actually teach': implementing a complex professional learning agenda in Scottish physical education, Physical Education and Sport Pedagogy, 17 (2), 127-144.

Black, C., and Martin, C., 2015. Mental health and wellbeing among adolescents in Scotland: profile and trends, http://www.gov.scot/Resource/0048/00488358.pdf. [Accessed 6 November 2017].

Brewer, B., 2003. Physical education and sport, in: TGK. Bryce and WM. Humes, eds. Scottish education. Second edition: Post-devolution, Edinburgh: Edinburgh University Press, 588 -592.

Bryce, T., 2003. Could do better? Assessment in Scottish schools, in: TGK. Bryce and WM. Humes, eds. Scottish education. Second edition: Post-devolution, Edinburgh: Edinburgh University Press, $709-720$.

Cosma, A., Rhodes, G., Currie, C., and Inchley, J., 2016. Mental and emotional well-being in Scottish adolescents, http://www.cahru.org/content/03-publications/03-briefing-papers-andfactsheets/bp24.pdf. [Accessed 6 November 2017]. 
Cosma, A., Whitehead, R., Neville, F., Currie, D., and Inchley, J., 2017. Trends in bullying victimization in Scottish adolescents 1994-2014: changing associations with mental wellbeing, International journal of public health, 1-8.

Day, C. and Townsend, C., 2009. Practitioner action research: building and sustaining success through networked learning communities, in SE. Noffke and B. Somekh, eds. Handbook of Educational Action Research, London: Sage, 178-189.

Dewar, AMK. and Lawson, HA., 1984. The subjective warrant and recruitment into physical education, Quest, 36, 15-25.

Education Scotland., 2017. Benchmarks Physical Education. March 2017. https://education.gov.scot/improvement/Documents/HWBPhysicalEducationBenchmarksPDF.pd f. [Accessed 6 November 2017].

Enright, E., Hill, J., Stanford, R. and Gard, M., 2014. Looking beyond what's broken: towards an appreciative research agenda for physical education and sport pedagogy, Sport, Education and Society, 19 (7), 912-926.

Gallahue, D. L., Ozmun, J. C., and Goodway, J. D., 2012. Understanding Motor Development: Infants, children, adolescents, adults, 7th ed. New York: McGraw-Hill. 
Goodway, JD., and Rudisill, ME., 1997. Perceived physical competence and actual motor skill competence of African American preschool children, Adapted Physical Acitivty Quarterly, 14, 314-326.

Jess, M. and Collins, D., 2003. Primary Physical Education in Scotland: the Future in the Making, European Journal of Physical Education, 8 (2), 103-118.

Jess, M., Keay, J. and Carse, N., 2014. Primary physical education: a complex learning journey for children and teachers, Sport, Education and Society, 21 (7), 1018-1035.

Kirk, D., in press. School Physical Education, young people and social media: Pedagogical strategies for health and wellbeing, in V. Goodyear and K. Armour, eds. Young People, Social Media, Health and Wellbeing. London: Routledge.

Lawson, H.A., 1988. Occupational socialization, cultural studies and the physical education curriculum, Journal of Teaching in Physical Education, 7: 265-288.

Lopes, L., Santos, R., Pereira, B., and Lopes, V. P., 2013. Associations between gross Motor Coordination and Academic Achievement in elementary school children, Human Movement Science, 32 (1), 9-20. 
MacPhail, A., 2007. Teachers' views on the construction, management and delivery of an externally prescribed physical education curriculum: Higher Grade Physical Education, Physical Education and Sport Pedagogy, 12 (1), 43-60.

MacLean, J., Mulholland, R., Gray, S., and Horrell, A., 2013. Enabling curriculum change in physical education: the interplay between policy constructors and practitioners. Physical Education and Sport Pedagogy, 20 (1), 79-96.

MacMillan, P., 2017. Understanding physical education teachers' day-to-day practice:

Challenging the 'unfair' picture, in M. Thorburn, ed. Transformative Learning and Teaching in Physical Education, London: Routledge, 159-175.

Mitchell, F., Gray, S. and Inchley, J., 2015. 'This choice thing really works...'Changes in experiences and engagement of adolescent girls in physical education classes, during a schoolbased physical activity programme, Physical Education and Sport Pedagogy, 20 (6), 593-611.

Mitchell, F., Inchley, J., Fleming, J., and Currie, C., 2015. A socio-ecological approach to understanding adolescent girls' engagement and experiences in the PE environment: A case study design, Graduate Journal of Sport, Exercise and Physical Education Research, 3, 44-62.

Oliver, KL., and Kirk, D., 2015. Girls, Gender and Physical Education: An Activist Approach, London: Routledge. 
Piek, JP., Dawson, L., Smith, LM., and Gasson, N., 2008. The role of early fine and gross motor development on later motor and cognitive ability, Human Movement Science, 27 (5), 668-681.

Quennerstedt, M., 2008. Exploring the relation between physical activity and health—a salutogenic approach to physical education, Sport, Education and Society, 13 (3), 267-283.

Scottish Executive, 2006. A Curriculum for Excellence: Building the Curriculum 1: The contribution of curricular areas. https://www.education.gov.scot/Documents/btc1.pdf [accessed 11 November 2017].

Scottish Government, 2009. Curriculum for excellence: Building the curriculum 4: Skills for learning, skills for life and skills for work. https://www.education.gov.scot/Documents/btc4.pdf [Accessed 9 November 2017]

Scottish Qualifications Authority, 2017. National 5 and Higher Course Report 2017, Dalkeith: Scottish Qualifications Authority.

Scottish Qualifications Authority, 2014. Higher Physical Education Course Specification, Dalkeith: Scottish Qualifications Authority.

Siedentop, D., 1996. Valuing the Physically Active Life: Contemporary and future directions, Quest, 48 (3), 266-274. 
Siedentop, D., 1994. Sport education: Quality PE through positive sport experiences, Champaign: Human Kinetics.

Smith, I., 2013. Education provision: An overview, in TGK. Bryce, WM. Humes, D. Gillies and A. Kennedy, eds. Scottish Education Fourth Edition: Referendum, Edinburgh: Edinburgh University Press, 13-27.

Standal, OF., 2015. Phenomenology and Pedagogy in Physical Education, London: Routledge.

Stodden, DF, et al., 2008. A developmental perspective on the role of motor skill competence in physical activity: An emergent relationship, Quest, 60 (2), 290-306.

Teraoka, E., Bardid, F. and Kirk, D., 2017. Young people's affective development in physical education contexts. Paper presented to the Scottish Educational Research Association Annual Conference, University of West of Scotland, November.

Thorburn, M., 1999. 'Is it Real Physical Education Today?' Knowledge and understanding in Standard Grade, Higher Grade and Higher Still Physical Education, Scottish Journal of Physical Education, 27 (1), 19-29.

Thorburn, M., 2004. Providing 'Opportunity for All' through Higher Still: a continuing challenge for physical education in Scotland, Scottish Educational Review, 24, 66-78. 
Thorburn, M. and Collins, D., 2006. The effects of an integrated curriculum model on student learning and attainment, European Physical Education Review, 12 (1), 31-50.

Thorburn, M. and Gray, S., 2010. Physical Education: Picking up the baton, Edinburgh: Dunedin.

Thorburn, M., Carse, N., Jess, M., and Atencio, M., 2011. Translating change into improved practice, European Physical Education Review, 17 (3), 313-324.

Thorburn, M., Jess, M., and Atencio, M., 2011. Thinking differently about curriculum: analysing the potential contribution of physical education as part of 'health and wellbeing' during a time of revised curriculum ambitions in Scotland, Physical Education and Sport Pedagogy, 16 (4), 383398.

Thorburn, M., 2018. Ed. Wellbeing, Education and Contemporary Schooling, London: Routledge. 
Table 1. Example of an experience and outcome of health and wellbeing with corresponding benchmarks.

\begin{tabular}{|c|c|}
\hline Experience and Outcome & Benchmarks to support practitioners' professional judgment \\
\hline I am developing the skills & Demonstrates self-reliance and self-worth through engaging in \\
\hline to lead and recognise & challenging tasks. \\
\hline strengths of group & Demonstrates the value of positive relationships while working and \\
\hline members, including myself. & learning with others. \\
\hline I contribute to groups and & Constructs/co-constructs criteria to evaluate personal and group \\
\hline teams through my & performance. \\
\hline knowledge of individual & Self-assesses and acts as a peer assessor to provide constructive \\
\hline strengths, group tactics, and & feedback to modify/enhance performance. \\
\hline strategies. (HWB 3-23a) & $\begin{array}{l}\text { Takes the initiative to celebrate, value and build on achievements as } \\
\text { part of the learning journey. }\end{array}$ \\
\hline
\end{tabular}

